\section{A geoeconomia do etanol: as condicionantes e as oportunidades para a consolidação de um mercado global*}

\section{The geoeconomics of ethanol: the constraints and opportunities for the consolidation of a global market}

\section{Resumo}

Há potencial demanda crescente pelos biocombustíveis ditada, sobretudo, por Estados Unidos e União Europeia que na última década estabeleceram metas para o consumo de combustíveis renováveis. No entanto, o mercado global para os biocombustíveis ainda não se consolidou, em função das diversas barreiras técnicas e protecionistas que condicionam a sua formação. Em contrapartida, superando-se essas barreiras, há oportunidades claras de se explorar etanol de primeira geração produzido com base em cana-de-açúcar, enquanto se desenvolvem tecnologias para a produção economicamente viável de biocombustíveis de segunda geração. Diante disso, o objetivo deste artigo consiste em analisar a geoeconomia do etanol, considerando as condicionantes e as oportunidades para a ampliação desse mercado e também a África como uma fronteira para a diplomacia brasileira. Observou-se que a política diplomática brasileira de internacionalização do etanol perdeu força ao longo do governo Dilma Rousseff, enfraquecendo o projeto brasileiro de se tornar uma força hegemônica do etanol no mundo.

Palavras-chave: Geoeconomia. Etanol. Diplomacia brasileira. África.

\begin{abstract}
There is a growing potential demand for biofuels due to the targets for the consumption of renewable fuels set by European Union and United States in the last decade. However, the global market for biofuels is not consolidated yet, because of the technical and protectionist barriers that affect its materialization. If these barriers are overcome there are clear opportunities to explore first-generation ethanol produced from sugarcane, while the technologies for second generation biofuels production are being developed. Given these facts, the purpose of this paper is to analyze the geoeconomics of ethanol, considering the constraints and opportunities for extending this market and also analyzing Africa as a frontier for Brazil's diplomacy. It was concluded that the Brazilian diplomacy for internationalization of ethanol lost strength over government Dilma Rousseff, weakening the Brazilian project to become a hegemonic force of ethanol in the world.
\end{abstract}

Keywords: Geoeconomics. Ethanol. Brazilian diplomacy. Africa.
Recebido em: 09/08/2015.

Aprovado em: 25/09/2015.

1 É geógrafa, formada pela Universidade Federal do Rio de Janeiro (UFRJ) e Mestre em planejamento ambiental e energético, formada pelo PPE/COPPE/UFRJ. Trabalha como Assistente de Pesquisa no Instituto de Pesquisa Econômica Aplicada (Ipea), RJ. E-mail: emilyfbrandao@ gmail.com. 


\section{Introdução}

Diante da corrida pela segurança energética e da crise climática global, os biocombustíveis passaram a ser uma pauta prioritária nas discussões diplomáticas. Tendo em vista a diversificação de suas matrizes energéticas e também o alcance das metas estabelecidas no protocolo de Kyoto, os países do anexo $1^{2}$ vêm se preocupando cada vez mais em consumir biocombustíveis, no entanto esbarram na instabilidade do mercado de fontes renováveis que ainda encontra barreiras técnicas e protecionistas para se consolidar.

Apesar desses gargalos, a produção de etanol aumentou nos últimos anos, sobretudo, em função das atividades de Estados Unidos e Brasil, que são os principais agentes desse mercado. Nos anos mais recentes, a produção e o consumo de etanol aumentaram também na União Europeia (UE), na China, no Canadá, entre outros (EMPRESA DE PESQUISA ENERGÉTICA, 2015).

A convivência amigável com o meio ambiente é uma das principais razões pelo aumento da demanda pelos biocombustíveis e, nesse sentido, o etanol se destaca pela capacidade de reduzir a emissão de Gases de Efeito Estufa (GEE). Embora haja grande ênfase na promoção dos biocombustíveis com base no fator ambiental, a legitimidade destes vem sendo questionada. Problemáticas relacionadas ao uso de terras férteis para produção de bioenergia e não para o cultivo de alimentos (food vs. fuel), promoção da monocultura e a possibilidade de desmatamento constituem alguns dos fatores que embargam a legitimidade e a produção dos biocombustíveis em larga escala (PARTZSCH, 2009).

Diante desse quadro, o objetivo deste artigo consiste em analisar a geoeconomia do etanol, considerando as condicionantes e as oportunidades para a ampliação desse mercado. Com base nesse mapeamento, pretende-se discutir a emergência da África como uma fronteira para a diplomacia brasileira, por meio do avanço do etanol e das atividades desenvolvidas no continente durante o governo Lula.

2 Alemanha, Austrália, Áustria, Bélgica, Bielorrússia, Bulgária, Canadá, Croácia, Dinamarca, Eslováquia, Espanha, Estônia, EUA, Federação Russa, Finlândia, França, Grécia, Hungria, Irlanda, Islândia, Itália, Japão, Letônia, Liechtenstein, Lituânia, Luxemburgo, Mônaco, Nova Zelândia, Noruega, Países Baixos, Polônia, Portugal, Reino Unido, República Tcheca, Romênia, Suécia, Suíça, Ucrânia.
Este texto divide-se em cinco seções, incluindo a introdução. A segunda seção apresenta uma análise da situação do mercado do etanol para Brasil, Estados Unidos e União Europeia, com ênfase nos acontecimentos dos últimos 10 anos. Na terceira seção, é analisada a estratégia para a formação de um mercado global do etanol através da discussão das condicionantes e das oportunidades. A quarta seção apresenta uma discussão sobre a África vista como uma fronteira para o avanço do etanol, com destaque para as atividades brasileiras no continente. A quinta seção finaliza o trabalho com uma análise dos efeitos da crise do setor sucroalcooleiro sobre a política diplomática brasileira de promoção do etanol.

\section{0 mercado do etanol para Brasil, Estados Uni- dos e União Europeia}

As crises do petróleo, ocorridas na década de 1970, fizeram o mundo despertar para a necessidade de reduzir a dependência em relação aos derivados do petróleo, pois a concentração geográfica e a instabilidade ética, religiosa e política dos principais produtores eleva a instabilidade da oferta e consequentemente, dos preços do combustível. No entanto, o grande desafio global não se restringe a preocupação com a segurança energética, mas também com o viés ambiental da produção e do uso da energia. $\mathrm{O}$ padrão tradicional de desenvolvimento, com base no uso dos derivados do petróleo, tem implicações ambientais, sobretudo, no que diz respeito às emissões de GEE, que refletem no equilíbrio e na qualidade de vida no planeta.

Ao longo do século XXI a discussão em torno da crise climática global teve repercussão sobre a política energética em âmbito global. A redução das emissões de GEE passou a ser uma preocupação, sobretudo, dos países do anexo I, que para tanto buscam utilizar de tecnologias mais eficientes e substituir, progressivamente, o uso dos combustíveis fósseis por fontes renováveis e limpas de energia.

Diante dessa problemática os biocombustíveis se tornaram uma opção viável para os países do anexo I, justificando a necessidade de consolidação de um mercado global para esses produtos. A internacionalização da produção e do consumo do etanol foi uma das prioridades da política diplomática do governo Lula e, embora tenha perdido força ao longo do Governo Dilma Rousseff, continua tendo grande importância uma vez que caracteriza novas modalidades de Cooperação para o Desenvolvi- 
mento Internacional através da Cooperação Sul-Sul e da Cooperação Trilateral, que serão discutidas na seção 4 .

A principal característica do mercado do etanol é a concentração das atividades no Brasil e nos Estados Unidos. Juntos esses países foram responsáveis por $80 \%$ da produção e por $72 \%$ do consumo total de etanol combustível no mundo em 2014, no entanto, Estados Unidos produziu e consumiu mais etanol que o Brasil (ORGANISATION FOR ECONOMIC CO-OPERATION AND DEVELOPMENT, 2015). Em 2014 a produção e consumo norte-americanos foram de 57 e 53 bilhões de litros de etanol, respectivamente, enquanto produção e consumo brasileiros foram de 28 e 27 bilhões de litros de etanol, (ORGANISATION FOR ECONOMIC CO-OPERATION AND DEVELOPMENT, 2015). Na União Europeia o biodiesel é o biocombustível soberano, contudo, o consumo de etanol vem ganhando força ao longo dos últimos anos. A União Europeia se destaca por apresentar um potencial em se tornar um forte mercado consumidor de etanol, em função das medidas políticas adotadas recentemente, no entanto, em 2014, representou apenas $7 \%$ do consumo de etanol no mundo (ORGANISATION FOR ECONOMIC CO-OPERATION AND DEVELOPMENT, 2015).

Uma das razões que explicam a forte influência de Brasil e Estados Unidos nesse mercado é a já consolidada indústria e a experiência desses dois países. O interesse do Brasil nos biocombustíveis teve início na década de 1930, mas, somente após a ocorrência do primeiro choque do petróleo, em 1973, que o governo despertou para a necessidade de criar programas de segurança energética. Iniciava, assim, o lançamento de programas de incentivo a pesquisa e produção de combustíveis renováveis, a fim de diminuir a dependência do petróleo. Em 1975 surgiu um dos programas que mais prosperaram, o Proálcool, que, desde sua fundação, vem contribuindo para a economia por meio da redução de importações de petróleo e de seus derivados (GUSMÃO, 1986).

A primeira iniciativa relevante em prol do incentivo ao etanol nos Estados Unidos ocorreu com a criação do Energy Tax Act em 1978 que estabeleceu uma isenção fiscal de US\$ 0,40 por galão ${ }^{3}$ de etanol para o distribuidor atacadista que misturasse à gasolina $10 \%$ de etanol. A partir de 1980 a isenção passou a ser de US $\$ 0,45$ por ga-

31 galão corresponde a 3,7854 litros. lão e a tarifa cobrada pelo etanol importado de US $\$ 0,54$ por galão. No entanto, o protecionismo veio ao fim em 2011, quando o congresso norte-americano votou pela não renovação da concessão dos subsídios à indústria sucroalcooleira e a taxação do produto importado (AGÊNCIA NACIONAL DO PETRÓLEO, 2012).

Ambos os países apresentam baixos custos de produção, em comparação com os demais países produtores de etanol do mundo, no entanto o custo da produção brasileira é ainda mais baixo que o custo da produção norte-americana, pois o balanço energético que resulta da combinação dos processos agrícola e industrial do etanol de cana-de-açúcar é mais eficiente que o do etanol de milho. A cana-de-açúcar, após ser submetida à extração do caldo, disponibiliza biomassa para cogeração de energia, reduzindo os custos com energia elétrica, por exemplo. Já o milho não disponibiliza biomassa suficiente para ser reaproveitada na produção de energia, encarecendo o processo (MILANEZ et. al, 2014). Além disso, em média, a cana-de-açúcar produz 7 mil litros por hectare, quase duas vezes mais etanol do que um acre de milho, que produz 3,8 mil litros por hectare (GOLDENBERG, 2009).

O setor de transportes é o grande responsável pela demanda por etanol nos Estados Unidos, no Brasil e na UE, que já possuem um mercado interno consolidado em função dos mandatos de mistura de etanol à gasolina que são, respectivamente, de $15 \%, 25 \%$ e $5-7 \%$. No caso brasileiro, os veículos com motor flex-fuel, introduzidos no mercado em 2003, promovem a expansão da demanda por álcool desde então. Atualmente, mais de $96 \%$ do etanol consumido no Brasil é direcionado para o setor de transportes, e o restante do uso é direcionado para a indústria (BRASIL, 2013). Em 2012 os veículos flex-fuel representaram $87 \%$ dos carros vendidos no Brasil (ASSOCIAÇÃO NACIONAL DOS FABRICANTES DE VEÍCULOS AUTOMOTORES, 2013).

Os gráficos 1, 2, 3 e 4 apresentam dados referentes ao desempenho da produção, consumo, importação e exportação de etanol para Estados Unidos, Brasil e União Europeia entre 2005 e 2014. Com base nos gráficos, é possível observar que Estados Unidos, Brasil e União Europeia apresentaram desempenhos muito peculiares em relação a essas variáveis nos últimos dez anos.

Nos Estados Unidos, houve um constante aumento da produção e do consumo entre 2005 e 2010 em consequência das políticas adotadas no país. Em 2007 o Energy 
Independence and Securiry Act (EISA $\left.{ }^{4}\right)$ estabeleceu o mandato Renewable Fuel Standard (RFS2), que somente foi aprovado em 2010. O RFS2 definiu os níveis para a mistura de biocombustíveis à gasolina (15\%) e, além disso, estabeleceu metas para o consumo de combustíveis renováveis de 36 bilhões de galões (136 bilhões de litros), sendo 16 bilhões de litros de combustíveis avançados e celulósicos, até 2022 (NATIONAL RESEARCH COUNCIL, 2011).

Gráfico 1- produção de etanol por país/região em bilhões de litros (2005 -2014)

Produção de etanol

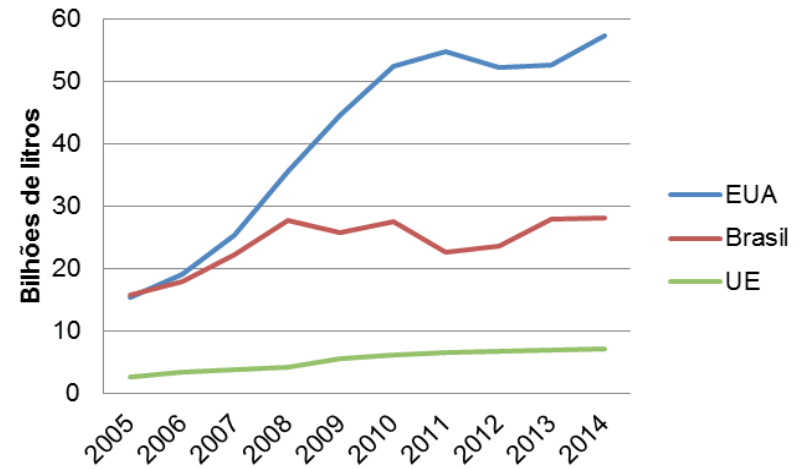

Fonte: (ORGANISATION FOR ECONOMIC CO-OPERATION AND DEVELOPMENT, 2015)

Gráfico 2- consumo de etanol por país/região em bilhões de litros (2005 - 2014)

4 Em 2005 foi criada a Energy Policy Act (EPAct 2005), regulamentação mais abrangente que a anterior, a Energy Tax Act. A EPAct estabeleceu o Renewable Fuel Standard (RFS1), mandato de mistura de biocombustíveis à gasolina por refinarias produtoras, distribuidores e importadores. No entanto, em 2007, foi lançado o Energy Independence and Securiry Act (EISA) que substituiu a EPAct e também criou a RFS2 (OECD, 2011).
Gráfico 3- importação de etanol por país/região em bilhões de litros (2005 -2014)

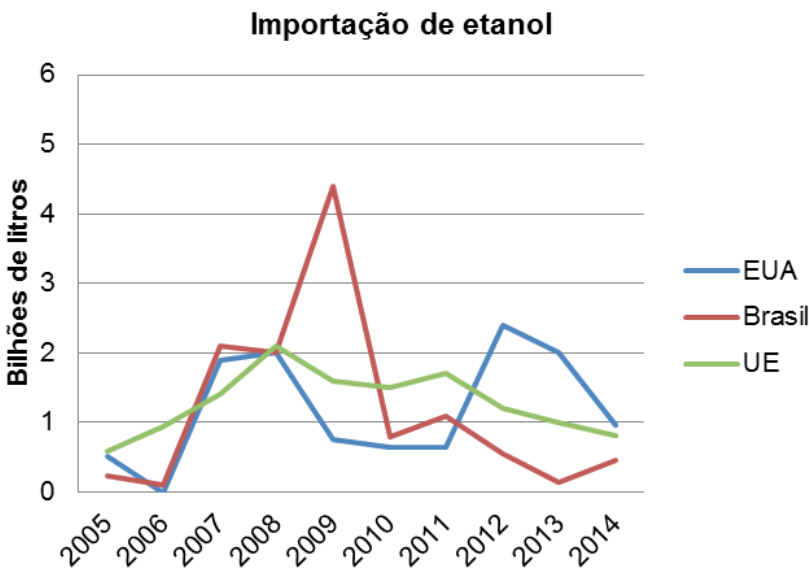

Fonte: (ORGANISATION FOR ECONOMIC CO-OPERATION AND DEVELOPMENT, 2015)

Gráfico 4- exportação de etanol por país/região em bilhões de litros (2005-2014)

Exportação de etanol

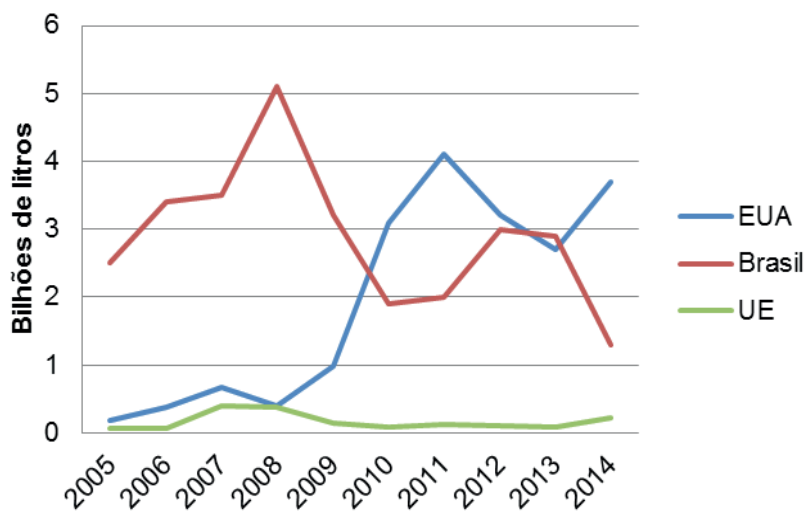

Fonte: (ORGANISATION FOR ECONOMIC CO-OPERATION AND DEVELOPMENT, 2015)

Apesar dos mandatos o consumo de etanol nos Estados Unidos manteve-se estável desde 2010. Acredita-se que isso se deve a crise financeira global, deflagrada em 2008, e a consequente desaceleração da economia norte-americana ocorrida entre 2008 e 2012 que prejudicou o consumo de gasolina no país. Além disso, houve uma redução do crédito para investimentos em novos projetos de biocombustíveis. Outra razão está na produção em excesso de etanol até 2010, muito acima do consumo e das metas estabelecidas pelos mandatos RFS2, o que ocasionou baixa rentabilidade da produção. Entre 2011 e 2012, quando a produção de etanol norte-americana apresentou queda em função da estiagem ocorrida sobre as regiões produtoras de milho (VIEIRA; CONTINI, 2013), o 
consumo se manteve estável devido à importação de etanol do Brasil que nesse período exportou 2,7 bilhões de litros de etanol para os Estados Unidos (BRASIL, 2015).

O Brasil, que por muitos anos foi o maior exportador de etanol do mundo, sentiu os impactos da crise a partir de 2008, apresentando quedas no volume de exportação de 60\% entre 2009 e 2010. No entanto, entre 2003 e 2009, a indústria sucroalcooleira viveu um dos melhores períodos, sobretudo, em função dos veículos flex-fuel e do apoio do governo, que ajustou o preço da gasolina para dar mais competitividade ao etanol. Com esse estímulo, o consumo de etanol passou de 34\% em 2005 para 50\% em 2008 (UNIÃO DA INDÚSTRIA DE CANA DE AÇÚCAR, 2015). O etanol apresentou-se como alternativa competitiva em relação à gasolina entre 2003 e 2010, contudo, após esse período, o seu preço aumentou. As oscilações observadas nas curvas brasileiras de produção, consumo, exportação e importação podem ser explicadas pela crise financeira global e por fatores internos que desencadearam na crise do setor sucroalcooleiro.

Em face da crise global, o governo buscou incentivar a demanda por etanol reduzindo o IPI sobre os veículos e expandindo o crédito para compra de automóveis. No entanto, paralelamente, houve redução de investimentos em renovação de canaviais, que, a partir de então, passaram a apresentar baixa produtividade. Outra iniciativa do governo para controlar a pressão inflacionária foi o ajuste de preços, por meio da redução para zero da Contribuição de Intervenção no Domínio Econômico (CIDE) que incide sobre a gasolina. Como resultado o etanol perdeu o diferencial tributário que garantia a competitividade do produto, cujo consumo é vantajoso somente quando o seu preço é 30\% mais baixo que o preço da gasolina, em função da menor eficiência energética do motor (ORGANISATION FOR ECONOMIC CO-OPERATION AND DEVELOPMENT, 2014). Por fim, chuvas em excesso em 2009 e seca em 2010 prejudicaram as safras de 2009/10 e de 2010/11, afetando a produção de etanol (RODRIGUES, 2012).

Entre 2012 e 2013, a produção brasileira de etanol aumentou e, em seguida, se estabilizou devido ao aumento do preço do açúcar no exterior ocorrido entre 2010 e 2011, que fez com que as usinas a priorizassem a produção de etanol (EMPRESA DE PESQUISA ENERGÉTICA, 2015). No gráfico 4 , observa-se que a curva brasileira de exportação de etanol sofreu brusca queda entre $2013 \mathrm{e}$ 2014 em função do aumento da produção de etanol norte-americana ocorrida no mesmo período (Gráfico 1).
$\mathrm{Na}$ União Europeia, a indústria sucroalcooleira é pequena, com produção de 7,1 e consumo de 8 bilhões de litros de etanol em 2014 (ORGANISATION FOR ECONOMIC CO-OPERATION AND DEVELOPMENT, 2015). Em geral, utilizam-se trigo, milho e beterraba como matérias-primas e a produção apresenta altos custos, sendo $30 \%$ mais cara do que a produção brasileira (WIESENTHAL et al., 2009). No entanto, a capacidade produtiva de etanol vem aumentando, pois em 2006 foram produzidos 2,1 bilhões de litros e em 2012, 8,5 bilhões de litros de etanol. A maior parte da capacidade produtiva está instalada na França, Holanda, Alemanha, Reino Unido, Polônia e Espanha. Embora haja participação modesta da União Europeia no mercado global de etanol, é importante ressaltar que os compromissos assumidos no Protocolo de Kyoto ditam a elaboração de medidas políticas que visam a redução de GEE, com destaque para o Renewable Energy Directive (RED) - Diretiva de Energia Renovável. ${ }^{5}$

Em 2003, a Comissão Europeia estabeleceu a Diretiva 2003/30/CE, cuja meta era a mistura de 5,75\% de etanol aos combustíveis fósseis a ser alcançada em 2010 (COMISSÃO EUROPEIA, 2003). Buscando complementar esta diretiva, em 2009, a Comissão europeia elaborou as Diretivas 2009/28/CE e 2009/29/CE, cujos objetivos devem ser alcançados até 2020. As principais metas são de substituição de $20 \%$ da sua matriz energética por fontes renováveis (no setor de transportes esta substituição terá que ser de 10\%), redução de GEE em $20 \%$ em relação ao que foi emitido em 1990 e mistura de 10\% v/v de etanol à gasolina (desses 7,5\% seriam biocombustíveis convencionais e os $2,5 \%$ restantes biocombustíveis avançados) (COMISSÃO EUROPEIA, 2009a; COMISSÃO EUROPEIA, 2009b).

Nos gráficos 1 e 2, referentes consumo e na produção de etanol, percebe-se que o desempenho da União Europeia, ao longo dos últimos 10 anos, apresentou um padrão: nos primeiros cinco anos a produção e o consumo foram maiores, com média anual de crescimento de 19\% e $21 \%$, respectivamente, sobretudo, em função das diretivas de incentivo à produção e consumo de etanol, no entanto, nos últimos cinco anos, tanto a produção como o consumo estabilizam, apresentando taxas médias anuais de crescimento mais baixas que as dos anos anteriores, com 4,7\%

5 Conjunto de normas que estabelecem metas obrigatórias para o uso de fontes renováveis de energia nos países- membros da UE até 2020. 
e 10,1\% (ORGANISATION FOR ECONOMIC CO-OPERATION AND DEVELOPMENT, 2015). Essa retração se deve à crise financeira global, que ocasionou redução dos subsídios e declínio do número de projetos em $29 \%$, entre 2008 e 2012. A outra razão para a desaceleração do setor sucroalcooleiro está na repressão ao consumo do etanol de primeira geração, devido ao questionamento da legitimidade ambiental dos biocombustíveis. Tendo em vista a garantia da sustentabilidade dos biocombustíveis, está previsto, no artigo $17^{\circ}$ da Diretiva 2009/28/CE, que até 2017 os biocombustíveis consumidos terão que apresentar uma redução de, no mínimo, de 35\% das emissões de GEE em seu ciclo de vida em relação ao combustível fóssil (COMISSÃO EUROPEIA, 2009a). A partir de 2017, a redução de GEE será de 50\% e de 60\% (COMISSÃO EUROPEIA, 2009a). Além disso, há estímulo à produção de etanol de segunda geração, ${ }^{6}$ que ainda encontra dificuldades tecnológicas para se consolidar e, portanto, apresenta baixa produtividade (FLACH et al., 2014).

\section{Estratégia para a formação de um mercado glo- bal do etanol: condicionantes e oportunidades}

O desenvolvimento de um mercado a níveis globais requer que existam demanda e oferta. $\mathrm{O}$ interesse pelos biocombustíveis estimula a adoção de medidas políticas de incentivo à produção e o consumo destes, favorecendo o desenvolvimento de uma demanda potencial para o produto. No entanto, a produção do etanol ainda é limitada a poucos países, com destaque para Estados Unidos e Brasil que são os players desse mercado. Dessa forma, ainda que a demanda apresente potencial de crescimento, a oferta constitui um gargalo. Um mercado exige grande número de participantes, tanto na produção como no consumo, como forma de garantir a estabilidade de preços. Superando-se as barreiras técnicas e protecionistas que embargam a formação de um mercado global para o etanol, uma opção seria a diversificação da produção por meio da participação de novos países produtores. Nessa seção serão discutidas as condicionantes e oportunidades que norteiam o desenvolvimento do mercado global do etanol.

6 O etanol de segunda geração, ou etanol celulósico, é um tipo de biocombustível produzido a partir material lignocelulósico, como bagaço excedente e resíduos como a palha, por meio, sobretudo, de um processo de hidrólise enzimática (RAELE et al., 2014).

\subsection{Condicionantes}

A característica de um mercado regional, cujas atividades são concentradas nos Estados Unidos e Brasil, funcionam como um incentivo a participação de novos produtores, mas ao mesmo tempo dificulta que esses novos participantes se adaptem, devido aos altos custos iniciais de produção que encareceriam o produto.

Pressionados pela necessidade de reduzir as emissões de GEE e pelos debates food vs. fuel os Estados Unidos e a União Europeia, passaram a desenvolver medidas políticas para incentivar uma produção sustentável dos biocombustíveis. Embora os critérios de sustentabilidade, presentes nas regulamentações norte-americana e europeia (RFS2 e Diretivas, respectivamente), possuam importância na contribuição ambiental dos biocombustíveis, também exigem uma maior complexidade do mercado do etanol, podendo representar barreiras técnicas ao comércio e à entrada de novos países produtores no mercado.

Além de estabelecer metas para o consumo de combustíveis renováveis, já mencionadas na sessão 2 , a RFS2 prevê a redução das emissões de GEE, por meio do uso de biocombustíveis gerados a partir determinadas matérias primas e/ou de produção sustentável. A classificação dos biocombustíveis, a definição de cada um e as metas a serem alcançadas podem ser observadas na tabela 1 .

Tabela 1 - Classificação dos biocombustíveis e metas para o consumo até 2022, segundo o RFS2

\begin{tabular}{|c|c|c|c|c|}
\hline Combustível & Significado & $\begin{array}{c}\text { Matérias- } \\
\text { primas }\end{array}$ & $\begin{array}{c}\text { Redução de } \\
\text { emissões de GEE } \\
\text { em relação aos } \\
\text { combustíveis } \\
\text { derivados do } \\
\text { petróleo }\end{array}$ & $\begin{array}{c}\text { Total a ser } \\
\text { consumido } \\
\text { até } 2022 \\
\text { (em bi de } \\
\text { litros) }\end{array}$ \\
\hline $\begin{array}{c}\text { Conventional } \\
\text { biofuels }\end{array}$ & $\begin{array}{c}\text { Qualquer } \\
\text { biocombustível - } \\
\text { etanol de primeira } \\
\text { geração produzido a } \\
\text { partir do milho }\end{array}$ & Milho & $\begin{array}{l}\text { Pelo menos } 20 \% \\
\text { de redução }\end{array}$ & 56,7 \\
\hline $\begin{array}{l}\text { Advanced } \\
\text { biofuels }\end{array}$ & $\begin{array}{c}\text { Inclui } \\
\text { biocombustível } \\
\text { celulósico, biodiesel } \\
\text { com base biomassa. }\end{array}$ & $\begin{array}{l}\text { Cana-de- } \\
\text { açúcar }\end{array}$ & $\begin{array}{l}\text { Pelo menos 50\% } \\
\text { de redução }\end{array}$ & 15,1 \\
\hline $\begin{array}{l}\text { Biomass- } \\
\text { Based Diesel } \\
\text { (subset of } \\
\text { advanced) }\end{array}$ & $\begin{array}{c}\text { Biodiesel produzido } \\
\text { a partir de plantas, } \\
\text { óleos ou gordura } \\
\text { animal }\end{array}$ & $\begin{array}{l}\text { Soja, } \\
\text { palma e } \\
\text { canola }\end{array}$ & $\begin{array}{l}\text { Pelo menos 50\% } \\
\text { de redução }\end{array}$ & 3,7 \\
\hline $\begin{array}{l}\text { Cellulosic } \\
\text { Biofuel } \\
\text { (subset } \\
\text { of advanced) }\end{array}$ & $\begin{array}{l}\text { Combustível } \\
\text { derivado de tecidos } \\
\text { estruturais de } \\
\text { resíduos vegetais }\end{array}$ & $\begin{array}{l}\text { Palha e } \\
\text { sabugo } \\
\text { de milho, } \\
\text { alga, } \\
\text { madeira }\end{array}$ & $\begin{array}{l}\text { Pelo menos } 60 \% \\
\text { de redução }\end{array}$ & 60,5 \\
\hline
\end{tabular}

Como observado na Tabela 1, o etanol de milho é classificado como um biocombustível convencional e apresenta, em todo o seu ciclo de vida, pelo menos $20 \%$ 
de redução de emissão de GEE (NATIONAL RESEARCH COUNCIL, 2011). No entanto, a meta para o seu consumo é de 56,7 bilhões de litros, ou seja, muito superior às metas estabelecidas para o consumo de biocombustíveis avançados e de diesel com base na biomassa, apesar destes últimos contribuírem mais para a redução das emissões de GEE. Embora não haja restrições ao consumo de etanol importado por meio de taxação nos Estados Unidos, essa meta estimula o consumo de etanol produzido internamente.

Para alcançar o nível de redução de emissões de GEE previsto na a Diretiva 2009/29/CE, a Comissão Europeia criou a Diretiva 2009/30/CE que estabelece medidas de descarbonização para a redução de emissões no setor de transportes como, por exemplo, o uso de biocombustíveis e de carros elétricos (COMISSÃO EUROPEIA, 2009c). Ademais, propôs que os produtores de biocombustíveis (inclusive os fornecedores externos) monitorassem os GEE's emitidos em todo seu ciclo de vida, reportassem em relatórios e assumissem medidas para o controle das emissões (COMISSÃO EUROPEIA, 2009c). Nos relatórios devem-se informar a quantidade total de combustíveis ou energias fornecidas e informações sobre o local onde foi adquirido o produto e sobre as emissões de GEE ao longo do ciclo de vida (COMISSÃO EUROPEIA, 2009c). Tudo isso encarece o produto final e, consequentemente, dificulta importação de biocombustíveis por parte da União Europeia.

A entrada de biocombustíveis na União Europeia está condicionada a determinação dos critérios de sustentabilidade. O cálculo que contabiliza as emissões de GEE inclui formas de emissão direta e indireta. As emissões indiretas são calculadas por meio da metodologia Indirect Land Use Changes (iLUC) e se referem às mudanças do uso da terra. Parte-se do pressuposto que a crescente demanda por biocombustíveis exigirá da indústria a expansão de área plantada. Com isso, haveria deslocamento de cultivos alimentares e de pastagens, gerando maior pressão sobre áreas de alta biodiversidade. Esse fenômeno, portanto, causaria efeito contrário ao que a UE buscaria, pois invalidaria a contribuição dos biocombustíveis no contexto de redução de GEE da Comunidade Europeia.

Essas exigências presentes nas Diretivas 2009/29/ CE e 2009/30/CE estão incluídas em certificados que passaram a ser concedidos pela Comissão Europeia em julho de 2011, são eles: Better Sugarcane Initiative (Bonsucro), ISCC, RSB, The Roundatable on Responsible Soy (RTRS),
The Biomass Biofuels voluntary scheme (2BSvs), The Abengoa RED Bioenergy Sustainability Assurance (RSBA) $e$ The Greenergy Brazilian Bioethanol verification programme (Greenergy) (EUROPEAN COMISSION ENERGY, 2011).

A existência dessas medidas e o seu cumprimento mostra comprometimento dos países com o desenvolvimento de uma grande indústria baseada nos moldes da sustentabilidade, respeitando aspectos sociais e ambientais. No entanto, deve-se atentar para a possibilidade de que essas medidas, na prática, possam representar barreiras técnicas ao desenvolvimento do mercado global de etanol. A disseminação de certificações pelo mundo pode acabar não sendo eficiente, pois afeta a credibilidade de sua adoção, podendo desenvolver nichos de mercados, encarecimento da produção, dificuldade de participação de novos produtores e anulação ou redução dos benefícios de uma possível redução das barreiras tarifárias (WORLD TRADE ORGANIZATION, 2007; ZARRILLI; BURNETT, 2008).

Essas barreiras técnicas que possivelmente poderão surgir ou que já estão impondo dificuldades ao mercado enfatizam ainda mais a necessidade de haver um sistema de padronização da produção, de modo a reduzir incertezas para produtores e consumidores. A padronização do etanol possibilitaria a homogeneização do produto, segundo Howse (2006). Atualmente, cada um dos países produtores de etanol apresenta uma especificação distinta, sem padrões. A padronização viabilizaria a classificação do etanol no Sistema Harmonizado de Designação e de Codificação de Mercadorias (SH) (Harmonized Commodity Description and Coding System ou HS classification), ${ }^{7}$ que é utilizado pela Organização Mundial do Comércio (OMC) para estabelecer limites de cobranças tarifárias para os produtos comercializados. Com os limites tarifários (bound tariffs), amplia-se a estabilidade do mercado para comerciantes e investidores, garantindo que barreiras comerciais não oscilem arbitrariamente (WORLD TRADE ORGANIZATION, 2007).

O Sistema Harmonizado de Designação e de Codificação de Mercadorias (SH) é uma nomenclatura internacional e multipropósito de produtos desenvolvido pela World Customs Organization (WCO). É composto por cerca de cinco mil grupos de commodities; cada uma identificada por um código de seis dígitos. O sistema é utilizado por mais de duzentos países e economias como base para as suas tarifas aduaneiras e para as estatísticas de comércio internacional. Mais de $98 \%$ das mercadorias comercializadas no mercado internacional são classificadas em termos da SH (WCO, 2015). 
Além das barreiras técnicas, a existência de barreiras protecionistas dificulta o comércio de biocombustíveis, pois elevam seus preços. Diferentemente dos EUA, os produtores Europeus, ainda que protegidos pelas barreiras protecionistas, apresentam dificuldades em aumentar a produção de biocombustíveis de primeira geração e, consequentemente, necessitam importar. Isso porque as características bioclimáticas e a disponibilidade de terra na Europa constituem condicionantes para a produção de biocombustíveis de primeira geração em larga escala. Diante disso, o etanol brasileiro poderia ser uma opção para a União Europeia, pois além de reduzir em mais de 50\% as emissões de GEE em relação aos combustíveis fósseis, enquadrando-se nos critérios de sustentabilidade estabelecidos pela Comissão Europeia, grande parte das usinas produtoras de etanol localizadas no Brasil possui certificação Bonsucro (UNIÃO DA INDÚSTRIA DE CANA DE AÇÚCAR, 2012). No entanto, com taxas de US\$ 0,24 por litro para o etanol etílico não desnaturado e US\$ 0,13 por litro para o etanol etílico e aguardentes, desnaturados (BRASIL, 2013), as exportações brasileiras para a União Europeia que em 2007 foram de 1,1 milhões de litros declinaram para de 8,1 mil litros em 2014 (UNIÃO DA INDÚSTRIA DE CANA DE AÇÚCAR, 2015). Há uma clara intenção de limitar as importações brasileiras, cujo etanol é mais barato, protegendo, assim, a indústria local.

\subsection{Oportunidades}

O momento atual é oportuno para estimular a produção de etanol no mundo, uma vez que há uma potencial demanda em crescimento pelo biocombustível, sobretudo, nos Estados Unidos e na União Europeia, que estabeleceram metas para o seu consumo. Essas medidas políticas de incentivo ao consumo e produção de biocombustíveis se tornaram uma possibilidade para os países desenvolvidos diversificarem suas matrizes energéticas, de modo a ampliarem a segurança energética e reduzirem as emissões de GEE. No entanto, como mencionado, há barreiras técnicas que dificultam a comercialização do etanol, como é o caso dos critérios de sustentabilidade.

Os biocombustíveis de segunda geração são privilegiados por essas nações, pois não exercem pressão sobre os recursos naturais e sobre os preços das commodities agrícolas. A produção de etanol de segunda geração em larga escala descentralizaria a oferta de biocombustíveis e, consequentemente, fortaleceria o mercado, porém há uma demanda tecnológica que condiciona a viabilidade econômica desse biocombustível. Atualmente, existem esforços em Pesquisa, Desenvolvimento e Inovação (PD\&I) visando o melhoramento dos métodos, sobretudo o de hidrólise enzimática. Segundo Nyko (2010), os EUA e a UE se destacam pelos investimentos públicos alocados no desenvolvimento de tecnologia para a produção de etanol de segunda geração, contudo, os resultados até então alcançados não são muito expressivos, pois o grande desafio é identificar uma biomassa economicamente competitiva. Em contrapartida, os avanços brasileiros nessa área são mais significativos, em virtude da alta produtividade agrícola da cana-de-açúcar, apesar dos baixos investimentos. Diante disso, segundo Goldemberg (2009), até que se atinja uma maturidade tecnológica o etanol de primeira geração poderá ser explorado se houver ganhos de produtividade e da expansão geográfica da produção de cana.

Desde o surgimento do Proálcool até 2009 a produtividade média brasileira aumentou em $4 \%$ ao ano em ganhos na produção agrícola e no processo industrial, segundo Goldemberg (2009). Os ganhos de produtividade na agricultura estiveram relacionados à diversificação e seleção das variedades de cana que, em 1984, eram 6 e, atualmente, são mais de 500 (MACEDO, 2005). A diversificação de variedades possibilitou aumento da produtividade e maior resistência contra pragas e doenças (GOLDEMBERG, 2009). Após 2009, no entanto, houve uma queda da produtividade em função dos eventos que desencadearam na crise do setor sucroalcooleiro no Brasil, já discutidos na seção 2. Apesar da crise o Brasil possui capacidade técnica para voltar aos níveis de crescimento de antes.

Por ser um combustível gerado a partir de uma matéria-prima agrícola, a produção de etanol exige certas condições, como disponibilidade de terras, sobretudo, áreas desflorestadas e de uso da pecuária, clima e temperatura apropriados e, nesse caso, os países do hemisfério sul são os mais indicados, pois apresentam essas particularidades, segundo Mathews (2007).

Segundo Goldemberg (2009) a cana-de-açúcar é cultivada em mais de cem países, no entanto, três quartos da produção mundial estão concentrados em oito países. Na Tabela 2, é possível observar o volume de produção de cana-de-açúcar e de etanol dos oito maiores produtores de cana do mundo em 2014. 
Tabela 2 - Produções de cana-de-açúcar (em milhões de toneladas) e de etanol (em milhões de litros) em 2014 por país

\begin{tabular}{ccc}
\hline & Cana-de-açúcar & Etanol \\
\hline Brasil & 632,4 & 28230,00 \\
\hline Índia & 342,2 & 2274,40 \\
\hline China & 125,9 & 7506,48 \\
\hline Tailândia & 107,6 & 1460,00 \\
\hline Paquistão & 64,2 & 510,56 \\
\hline México & 61,2 & 68,58 \\
\hline Colômbia & 35,5 & 428,44 \\
\hline Austrália & 31,6 & 341,66 \\
\hline
\end{tabular}

Fonte: (ORGANISATION FOR ECONOMIC CO-OPERATION AND DEVELOPMENT, 2015)

O Brasil é o maior produtor de cana-de-açúcar e etanol. A índia se destaca pela produção de cana, sendo a segunda maior do mundo, no entanto, mesmo com menos da metade da produção indiana de cana-de-açúcar a China produz quase quatro vezes mais etanol do que este país. Em 2014 a Índia produziu 26,3 milhões de toneladas de açúcar, enquanto que china produziu 13,2 milhões de toneladas, a metade. Percebe-se, claramente, que há uma diferença de prioridades, pois a China reúne esforços para produzir etanol, enquanto que a Índia possui foco na produção de açúcar. Nesse contexto, Coelho (2006) ressalta que os países produtores de cana-de-açúcar deveriam ser estimulados a produzirem etanol, caso tivessem interesse em reduzir a dependência em relação aos derivados de petróleo. Esse estímulo pode ser em forma de cooperação técnica horizontal (acordos bilaterais e trilaterais), investimentos públicos e privados diretos, avanços em pesquisa para a verificação de viabilidade etc.

\section{4 África, uma fronteira para a diplomacia brasi- leira: o avanço do etanol durante o governo Lula}

O governo brasileiro emprega diferentes estratégias em prol da "comoditização" do etanol, estimulando potenciais consumidores e/ ou produtores de modo a diversificar o mercado e gerar maior estabilidade das relações comerciais. Um dos principais motores do processo de desenvolvimento do Brasil do século XX foi o avanço da produção agrícola como resultado da intensificação do uso dos biocombustíveis. Dessa forma, a difusão do know-how tornou-se um dos pilares para o projeto brasileiro, possibilitando investimento direto em outros países e regiões, com destaque para os países da África.
O estreitamento das relações bilaterais e multilaterais com os países africanos ocorreu principalmente durante o governo Lula. Os países africanos apresentam grande potencial para os biocombustíveis, em razão de fatores geoestratégicos, tais como: condições edafoclimáticas favoráveis, disponibilidade de terra (não ocupadas ou arrendadas a preços muito baixos), mão de obra nas áreas rurais, interesse dos governos nas tecnologias para produção de alimento e bioenergia e afinidades em função da cooperação Sul-Sul (SCHLESINGER, 2012). O privilégio de poder ter acesso ao mercado da União Europeia livre de impostos torna a África ainda mais atraente para os investidores. Esta vantagem se deve aos diversos acordos comerciais efetuados entre os países do continente africano e a UE. O mercado dos EUA também permite fácil acesso de produtos produzidos na África, com tarifas reduzidas para o bioetanol. Contudo, para entrarem nesses mercados é preciso que os produtos produzidos na África estejam de acordo com os critérios de sustentabilidade definidos pelos países do Norte (MITCHELL, 2010).

Os biocombustíveis estão vinculados direta ou indiretamente a uma infinidade de setores, incluindo energia, indústria, agricultura, investigação científica e ajuda ao desenvolvimento e, além disso, envolve a participação de ministérios e atores das esferas pública e privada (DALGAARD, 2012). A primeira fase de atividades envolveu a ação de agências e instituições de pesquisa brasileiras na África para verificar a viabilidade em conciliar a produção de biocombustíveis e de alimentos.

A ida da Empresa Brasileira de Pesquisa Agropecuária (Embrapa) para a África em 2008 foi uma das primeiras iniciativas que marcaram o interesse brasileiro. O escritório piloto, localizado em Acra (Gana), oferece treinamentos técnicos voltados para o desenvolvimento agrícola tropical. Em Moçambique, Mali e Senegal a Embrapa desenvolve pesquisas para verificar variedades de canas adaptáveis às condições climáticas destes países (BARBOSA, 2010). Essa tecnologia contribuiu para o aumento da produtividade dos cerrados brasileiros, levando os responsáveis políticos a considerar que poderia ser replicado em savanas de África (AMORIM, 2010).

Outra instituição que apresentou grande importância nesse primeiro momento do projeto de internacionalização do etanol foi a Fundação Getúlio Vargas (FGV), requisitada por diversos agentes brasileiros públicos e 
privados para realizar estudos de viabilidade em países que tem interesse em se envolver com biocombustíveis e implantar projetos, a partir das conclusões dos estudos (MARINHO, 2011). Outra tarefa da FGV foi conseguir financiamento de aproximadamente US\$ 1 bilhão, por meio de um fundo coordenado pelo DWS Investments, para a construção de usinas voltadas para a produção de etanol, um complexo de industrialização de soja e dez termelétricas movidas à biomassa (LEO, 2011).

A disponibilidade de financiamentos constitui um dos grandes desafios ao desenvolvimento do etanol na África. Nesse sentido, o Banco Nacional de Desenvolvimento Econômico e Social (BNDES) vem sendo um forte aliado do projeto, na medida em que fornece investimentos para o desenvolvimento de projetos voltados para a produção de etanol (CABRAL et al., 2013). Em 2006 o BNDES estabeleceu uma linha de crédito de 1,5 bilhão de dólares para investimentos em Angola, como parte do projeto de parceria estratégica entre Brasil e Angola para a produção de etanol (SANTOS, 2008). Em 2010 outra linha de crédito de 3.500 milhões dólares foi aberta para financiar ações das empresas atuantes em Gana e em Moçambique (BARROS, 2010). Em Junho de 2012, o BNDES assinou um memorando de entendimento com o Banco Africano de Desenvolvimento (BAD) para explorar investimentos em bioenergia e no ano seguinte foi lançado o escritório de representação do BNDES em Joanesburgo (THALER, 2013).

O projeto brasileiro de cooperação técnica para os biocombustíveis na África também inclui a participação de grupos empresariais interessados no setor sucroalcooleiro. Esta é uma oportunidade para a internacionalização das atividades, além de uma chance para conquista de novos mercados (NUNES, 2011). Os principais grupos empresariais privados brasileiros do setor sucroalcooleiro atuantes na África são ETH Bioenergia do grupo Norberto Odebrecht e Grupo Guarani, Dedini Indústria de Base e Sermatec Zanini (NUNES, 2011).

A ETH Bioenergia atua em Angola através da Companhia de Bionergia de Angola Ltda. (BioCom), uma joint venture formada entre as empresas angolanas Sonangol (20\%) e Damer (40\%) e a brasileira Odebrecht (40\%) (VAISMAN, 2010). Em Gana a ETH Bioenergia atua na construção de uma usina de açúcar e de álcool, por meio do financiamento concedido pelo
BNDES de cerca de US\$ 300 milhões (MORAES; MATTOS, 2012). A Guarani, que é subsidiária brasileira da Tereos, a Petrobrás biocombustíveis e a Petróleos de Moçambique (Petromoc) atuam produzindo açúcar e etanol em Moçambique através da Companhia de Sena (BARROS, 2011). A Dedini se dedica a construção de usinas de produção de açúcar, álcool e cogeração localizadas no Sudão e Moçambique (BATISTA, 2010). Por fim, a Sermatec Zanini é responsável pela exportação de equipamentos, como caldeiras e um difusor de cana, sobretudo para Angola para serem usados na BioCom (BATISTA, 2010).

Paralelamente a internacionalização das empresas privadas, o Brasil estabeleceu acordos de cooperação trilateral para a difusão do etanol, em que presta assistência com parceiros a um país beneficiário. Em 2007 Brasil e Estados Unidos assinaram um Memorando de Entendimento com o objetivo de promover a produção e o consumo de biocombustíveis na África, na América Central e no Caribe, por meio da realização de estudos de viabilidade e da prestação de assistência técnica (MORAES; MATTOS, 2012).

Em 2007 o Brasil firmou o Memorando de Entendimentos na Área de Biocombustíveis com a União Econômica e Monetária do Oeste Africano (UEMOA), ${ }^{8}$ para viabilizar a realização de estudos de viabilidade nos países da UEMOA, por meio do financiamento do BNDES (UNITED NATIONS CONFERENCE ON TRADE AND DEVELOPMENT, 2012).

Em 2009 foi assinado o acordo de Cooperação Trilateral Brasil-União Europeia-África, visando a elaboração de estudos de viabilidade para produção de etanol a partir da cana-de-açúcar e a implementação destes projetos (UNITED NATIONS CONFERENCE ON TRADE AND DEVELOPMENT, 2012).

Entre Índia, Brasil, África do Sul (IBAS) foi assinado em 2008 o Memorando de Entendimento sobre biocombustíveis com o objetivo de criar uma Força-Tarefa para proporcionar cooperação técnica no âmbito da IBAS e incentivar outros países a produzirem e consumirem biocombustíveis (UNITED NATIONS CONFERENCE ON TRADE AND DEVELOPMENT, 2012).

\footnotetext{
8 Países membros da União Econômica e Monetária do Oeste Africano (UEMOA): Benin, Burkina Faso, Costa do Marfim, Guiné-Bissau, Mali, Níger, Senegal e Togo.
} 


\section{Considerações finais}

Há uma perspectiva de crescimento da demanda global pelo etanol, previsto para acontecer até 2022, em função das metas de consumo de biocombustíveis estabelecidas por Estados Unidos e União Europeia. Apesar das oportunidades de diversificação da produção desse mercado, por meio do estímulo à participação de novos países produtores de etanol, ainda existem barreiras que impedem seu desenvolvimento pleno. Os critérios de sustentabilidade estabelecidos por Estados Unidos e União Europeia, por exemplo, ao mesmo tempo em que indicam uma preocupação com as questões ambientais e sociais podem constituir barreiras técnicas ao avanço da comercialização do etanol, visto que induzem a um encarecimento da produção. As barreiras protecionistas também encarecem o produto e, ao final, acaba sendo uma dificuldade para os países exportadores e para o próprio importador, cuja capacidade produtiva de biocombustíveis é limitada e por essa razão necessita importar para atingir as metas de consumo estabelecidas.

Todos esses gargalos que restringem a comercialização dos biocombustíveis e, consequentemente, favorecem a concentração do mercado só reforçam ainda mais necessidade de haver uma padronização da produção, pois então seria possível classificar o etanol no SH, que é utilizado pela OMC para estabelecer limites de cobranças tarifárias para os produtos comercializados.

Em face da necessidade de expandir a oferta e a demanda pelo etanol o Brasil vem investindo na estratégia de estimular a participação de países em desenvolvimento nesse mercado. Essas iniciativas, no entanto, ocorreram ao longo do governo Lula, e perderam força durante o governo Dilma Rousseff, que priorizou o petróleo e o pré-sal (AGUIAR, 2014). Além disso, uma série de fatores causou uma crise profunda no setor sucroalcooleiro brasileiro, como os eventos climáticos que prejudicaram a produção de cana em 2009 e 2010, a crise econômica mundial que ocasionou retração dos fluxos de investimentos estrangeiros no setor, reduzindo as atividades de diversas unidades de produção e a política de o controle da inflação através do congelamento do preço da gasolina e de redução da CIDE.

Inevitavelmente, a crise do setor afetou a política brasileira de diplomacia do etanol. Nos últimos anos, houve estagnação das parcerias estabelecidas, gerando desconfiança entre os parceiros africanos acerca da ca- pacidade brasileira de liderar a campanha de promoção do etanol. Não faltam recursos científicos para o Brasil avançar, mas o abalo da crise gerou restrições orçamentárias importantes e isso vem limitando a capacidade de atuação dos atores do setor público e privado no exterior. Todos estes fatores contribuíram para que o Brasil não aproveitasse uma grande oportunidade de se tornar uma força hegemônica do etanol no mercado global.

\section{Referências}

AGÊNCIA NACIONAL DO PETRÓLEO. Boletim anual de preços: preços do petróleo, gás natural e combustíveis nos mercados nacional e internacional. Rio de Janeiro: ANP, 2012. Disponível em: <file://C:/Users/maria/ Downloads/59757.pdf.>. Acesso em: 06 jul. 2015.

AGUIAR, I. D. Etanol atravessa sua pior crise. Valor Econômico, São Paulo, 28 abr. 2014. Disponível em: <http://www.udop.com.br/index. php?item $=$ noticias\&cod=1113024>. Acesso em: 29 jul. 2015.

AMORIM, C. Brazilian foreign policy under President Lula (2003-2010): an overview. Revista Brasileira de Política Internacional, Brasília, v. 53, n. spe, p. 214240, dez. 2010. Disponível em: <http://www.scielo.br/ scielo.php?script $=$ sci_arttext\&pid=S0034329 201000030 0013\&lng=en\&nrm=iso >. Acesso em: 23 jul. 2015.

ASSOCIAÇÃO NACIONAL DOS FABRICANTES DE VEÍCULOS AUTOMOTORES. Anuário da indústria automobilística brasileira. São Paulo: ANFAVEA, 2013. Disponível em: <http://www.anfavea.com.br/anuario. html $>$. Acesso em: 17 jun. 2015.

BARBOSA, L. A. Cooperação internacional na produção de etanol: limites e oportunidades. 2010. 103 f. Dissertação (Mestrado) - Escola de Economia de São Paulo, Fundação Getúlio Vargas, São Paulo, 2010. Disponível em: <http://ainfo. cnptia.embrapa.br/digital/bitstream/item/26573/1/tese. pdf $>$. Acesso em: 23 jul. 2015.

BARROS, B. Guarani e Petrobras estudam produzir etanol em Moçambique. Valor Econômico. São Paulo, 14 dez. 2011. Disponível em: $<$ http://www.valor.com.br/empresas/1137742/guarani-epetrobras-estudam-produzir-etanol-em-mocambique $>$. Acesso em: 20 jul. 2015.

BARROS, G. S. Participação do BNDES na África deverá dobrar até o fim do governo Lula, 2010. Disponível em: <http://colunistas. ig.com.br/guilhermebarros/2010/03/05/participacao-dobndes-na-africa-devera-dobrar-ate- o-fim-dogovernolula>. Acesso em: 27 jul. 2015. 
BATISTA, F. Indústria do Brasil de olho em projetos de usinas na África. Valor Econômico, São Paulo, 16 fev. 2010. Disponível em: <http://www.valor.com.br/ arquivo/810681/industrias-do-brasil-de-olho-emprojetos-de-usinas-na-africa>. Acesso em: 29 jul. 2015.

BRASIL. Ministério da Agricultura, Pecuária e Abastecimento. Anuário estatístico da agroenergia. Brasília: MAPA, 2015. Disponível em: <http://www. agricultura.gov.br/desenvolvimento-sustentavel/ agroenergia/estatistica>. Acesso em: 12 jul. 2015.

BRASIL. Ministério de Minas e Energia. Análise de conjuntura dos biocombustíveis, ano 2012. Brasília: MME/ EPE, 2013. Disponível em: <http://www.epe.gov.br/ Petroleo/Documents>. Acesso em: 07 jul. 2015.

CABRAL, L. et al. Brazil-Africa Agricultural Cooperation Encounters: drivers, narratives and imaginaries of Africa and development. Ids Bulletin, v. 44, n. 4, p. 53-68, jul. 2013. Disponível em: <http://onlinelibrary.wiley.com/ doi/10.1111/1759-5436.12042/abstract>. Acesso em: 25 jul. 2015.

COELHO, S. T. et al. Brazilian sugarcane ethanol: lessons learned. Energy for Sustainable Development, Amsterdam, v. 10, n. 2, p. 26-39, jun. 2006. Disponível em: <www. sciencedirect.com>. Acesso em: 18 jul. 2015.

COMISSÃO EUROPEIA. Diretiva 2003/30/CE do Parlamento Europeu e do Conselho, de 8 de maio de 2003: relativa à promoção da utilização de biocombustíveis ou de outros combustíveis renováveis nos transportes, 2003. Disponível em: <http://eur-lex.europa.eu/legal-content/ $\mathrm{PT} / \mathrm{TXT}$ /?uri=CELEX:32003L0030>. Acesso em: 16 jul. 2015.

COMISSÃO EUROPEIA. Diretiva 2009/28/CE do Parlamento Europeu e do Conselho, de 23de abril de 2009: relativa à promoção da utilização de energia proveniente de fontes renováveis que altera e subsequentemente revoga as Diretivas 2001/77/CE e 2003/30/CE, 2009a. Disponível em: <http://eurlex.europa.eu/LexUriServ/ LexUriServ.do?uri=OJ:L:2009:140:0016:0062:pt:PDF>. Acesso em: 16 jul. 2015.

COMISSÃO EUROPEIA. Diretiva 2009/29/CE do Parlamento Europeu e do Conselho de 23 de abril de 2009: altera a Diretiva 2003/87/CE a fim de melhorar e alargar o regime comunitário de comércio de licenças de emissão de gases com efeito de estufa, 2009b. Disponível em: <http://eur-lex.europa.eu/legal-content/ PT/TXT/?uri=CELEX:32009L0029>. Acesso em: 16 jul. 2015.
COMISSÃO EUROPEIA. Diretiva 2009/30/ CE do Parlamento Europeu e do Conselho, de 23 de abril de 2009: altera a Diretiva 98/70/CE no que se refere às especificações da gasolina e do gasóleo rodoviário e não rodoviário e à introdução de um mecanismo de monitorização e de redução das emissões de gases com efeito de estufa e que altera a Diretiva 1999/32/ $\mathrm{CE}$ do Conselho no que se refere às especificações dos combustíveis utilizados nas embarcações de navegação interior e que revoga a Diretiva 93/12/CEE, 2009c. Disponível em: <http://eurlex.europa.eu/LexUriServ/ LexUriServ.do?uri=OJ:L:2009:140:0088:0113:PT:PDF>. Acesso em: 17 jul. 2015.

DALGAARD, K. G. The energy statecraft of Brazil: promoting biofuels as an instrument of Brazilian foreign policy, 2003-2010. 2012. 230 f. Tese (Doutorado) London School Of Economics, Londres, 2012. Disponível em: <http://etheses.lse.ac.uk/585/1/Dalgaard_Energy_ Statecraft_Brazil_2012.pdf >. Acesso em: 22 jul. 2015.

EMPRESA DE PESQUISA ENERGÉTICA. Análise de conjuntura dos biocombustíveis: ano 2014. Rio de Janeiro: EPE, 2015. Disponível em: <http://www.epe. gov.br/Petroleo/Documents/Análise de Conjuntura dos Biocombustíveis - boletins periódicos/Análise de Conjuntura - Ano 2014.pdf>. Acesso em: 10 jun. 2015.

EUROPEAN COMISSION ENERGY. Renewable energy: sustainability schemes for biofuels, 2011. Disponível em: <http://ec.europa.eu/energy/renewables/biofuels/ sustainability_schemes_en.htm>. Acesso em: 18 jul. 2015.

FLACH, B.; BENDZ, K.; LIEBERZ, S. EU biofuels annual 2014 report: global agricultural information network, 2014. Disponível em: <http://gain.fas.usda. gov/RecentGAINPublications/BiofuelsAnnual_ SaoPauloTO_Brazil_7-25-2014.pdf $>$. Acesso em: 16 jul. 2015.

GOLDEMBERG, J. Os limites do etanol de primeira geração. Revista Opiniões, Ribeirão Preto, p. 18-20, jul./ set. 2009.

GUSMÃO, R. Avaliação do proálcool e suas perspectivas. 5. ed. São Paulo: Sopral, 1986.

HOWSE, R.; VAN BORK, P.; HEBEBRAND, C. WTO disciplines and biofuels: opportunities and constraints in the creation of a global marketplace. Washington: IPC, 2006. Disponível em: <http://www.agritrade.org/Publications/ DiscussionPapers/WTO_Disciplines_Biofuels.pdf $>$. Acesso em: 20 jul. 2015.

LEO, S. Rumo à África, a questão é financiamento. Valor Econômico, São Paulo, 21 nov. 2011. Disponível em: $<$ http://www8.valorinternational.com.br/brasil/1102188/ rumo-africa-questao-e-financiamento $>$. Acesso em: 25 jul. 2015. 
MARINHO, F. A. C. A cooperação entre Brasil e Estados Unidos na área de biocombustíveis. 2011.97f. Dissertação (Mestrado) - Pontifícia Universidade Católica, São Paulo, 2011. Disponível em: <http://repositorios.inmetro.gov. br/bitstream/10926/1259/1/Marinho_2011.pdf>. Acesso em: 24 jul. 2015.

MATHEWS, J. A. Biofuel: what a biopact between north and south could achieve. Energy Policy, Amsterdam, v. 35, n. 7, p. 3550-3570, jul. 2007. Disponível em: <www.sciencedirect. com>. Acesso em: 20 jul. 2015.

MIDIC/SECEX - Ministério do Desenvolvimento, Indústria e Comércio Exterior/Secretaria de Comércio Exterior. Estatísticas, 2013. Disponível em: <http://aliceweb2. mdic.gov.br//index/home>. Acesso em: 17 jul. 2015.

MILANEZ, A. Y. et al. A produção de etanol pela integração do milho-safrinha às usinas de cana-de-açúcar: avaliação ambiental, econômica e sugestões de política. Revista do BNDES, Rio de Janeiro, v. 41, p. 147-208, jun. 2014. Disponível em: <http://www.bndes.gov.br/SiteBNDES/ export/sites/default/bndes_pt/Galerias/Arquivos/conhecimento/revista/rev4104.pdf>. Acesso em: 07 jul. 2015.

MORAES, I. A.; MATTOS, R. B. Cooperação Brasil-África em biocombustíveis durante o governo Lula: uma parceria para o desenvolvimento. Revista Conjuntura Austral. Porto Alegre, v. 3, n. 13, p. 54-71, ago./set. 2012. Disponível em: <http://www.ufrgs. br/sebreei/2012/wp-content/uploads/2013/01/Isaias-de-MoraesBeatriz-Mattos.pdf>. Acesso em: 29 jul. 2015.

NATIONAL RESEARCH COUNCIL. Renewable fuel standard: potential economic and environmental effects of U.S. biofuel policy. Washington D.C: NRC, 2011. Disponível em: <http://dels.nas.edu/resources/static-assets/ materials-based-on-reports/reports-in-brief/Renewable-Fuel-Standard-Final.pdf>. Acesso em: 12 jul. 2015.

NUNES, F. África: projetos na área de etanol têm bom potencial. Valor Econômico, São Paulo, 27 nov. 2011. Disponível em: <http://www.valor.com.br/impresso/agronegocios/projetos-na-area-de-etanol-tem-bom potencial>. Acesso em: 28 jul. 2015.

NYKO, D. et al. A corrida tecnológica pelos biocombustíveis de segunda geração: uma perspectiva comparada. BNDES Setorial: Biocombustíveis, Rio de Janeiro, n. 32, p. 5-48, 2010. Disponível em: <http://www.bndes.gov.br/SiteBNDES/ export/sites/default/bndes_pt/Galerias/Arquivos/conhecimento/bnset/set32101.pdf>. Acesso em: 20 jul. 2015.

ORGANISATION FOR ECONOMIC CO-OPERATION AND DEVELOPMENT. Agricultural Outlook 20142023, 2014. Disponível em: <https://www.embrapa. br/documents/1024963/1025740/OECD-FAO_ Agricultural_Outlook_2014-2023/20082926-0f88-4159970a-2a1c65795c47>. Acesso em: 15 jul. 2015.
ORGANISATION FOR ECONOMIC CO-OPERATION AND DEVELOPMENT. Agricultural Outlook 2015-2024 - Database, 2015. Disponível em: <http://www.agrioutlook.org/database/>. Acesso em: 03 jun. 2015.

ORGANISATION FOR ECONOMIC CO-OPERATION AND DEVELOPMENT. Evaluation of agricultural policy reforms in the United States. Paris: OECD, 2011. Disponível em: <http://www.oecd.org/publications/evaluationof-agriculturalpolicy-reforms-in-the-united-states9789264096721-en.htm>. Acesso em: 12 jul. 2015.

RAELE, R. et al. Scenarios for the second generation ethanol in Brazil. Technological Forecasting And Social Change, Amsterdam, v. 87, p. 205-223, set. 2014. Disponível em: <http://www.sciencedirect.com>. Acesso em: 17 jul. 2015.

RODRIGUES, A. P. Setor sucroalcooleiro e a regulação do etanol. São Paulo: Única, 2012. Disponível em: <www. unica.com.br/download.php?idSecao=17\&id=24775593 $>$. Acesso em: 15 jul. 2015.

SANTOS, C. BNDES libera US\$ 1,5 bilhão para Angola. Valor Econômico, São Paulo, 10 jun. 2008. Disponível em: <http://g1.globo.com/Noticias/Economia_Negocios/0MU L595616-9356,00BNDES+LIBERA+US+BILHAO+PARA+ ANGOLA.html>. Acesso em: 25 jul. 2015.

THALER, K. Brazil, biofuels and food security in Mozambique. In:CHERU, F; MODI, R. (Org.). Agricultural development and food security in Africa. Londres: Zed Books, 2013. p. 145-158.

UNIÃODAINDÚSTRIADECANADEAÇÚCAR.Mesmo certificado, etanol brasileiro tem acesso a UE prejudicado por barreira comercial, 2012. Disponível em: <http:// www.unica.com.br/noticia/36949486920321033654/ mesmo-certificado-por-cento2C-etanol-brasileiro-temacesso-a-ue-prejudicado-por-barreira-comercial/>. Acesso em: 17 jul. 2015.

UNIÃO DA INDÚSTRIA DE CANA DE AÇÚCAR. Unicadata, 2015. Disponível em: <http://www.unicadata. com.br/>. Acesso em: 14 jul. 2015.

UNITED NATIONS CONFERENCE ON TRADE AND DEVELOPMENT. State ofsouth: south and triangular cooperation in the production, use and trade of sustainable biofuels, 2012. Disponível em: $<$ http://unctad. org/en/PublicationsLibrary/ditcted2011d10_en.pdf $>$. Acesso em: 29 jul. 2015.

VAISMAN, R. Cooperação Brasil-Angola na produção de etanol. Revista eletrônica ICTSD: International Centre for Trade and Sustainable Development, Genebra, v. 6, n. 1, abr. 2010. Disponível em: <http://ictsd.org/i/news/ pontes/74348/\#sthash.ufImk39H.dpuf $>$. Acesso em: 28 jul. 2015. 
VIEIRA, P. A.; CONTINI, E. Seca americana: implicações para o agronegócio. Agroanalisys, São Paulo, v. 33, n. 01, p. 19-20, jan. 2013. Disponível em: <http://www.agroanalysis.com.br/materia_detalhe.php?idMateria $=1392>$. Acesso em: 05 jul. 2015.

WIESENTHAL, T. et al. Biofuel support policies in Europe: lessons learnt for the long way ahead. Renewable and Sustainable Energy Reviews, Oxford, v. 13, n. 4, maio, 2009. Disponível em: <http://www.sciencedirect.com>. Acesso em: 15 jul. 2015.

WORLD TRADE ORGANIZATION. Understanding the WTO. 3. ed. Switzerland: WTO, 2007. Disponível em: $<$ http://www.wto.org>. Acesso em: 18 jan. 2015.
ZARRILLI, S.; BURNETT, J. Making certification work for sustainable development: the case of biofuels. New York: United Nations, 2008. Disponível em: <http://www.unctad.org/en/ docs/ditcted20081_en.pdf>. Acesso em: 20 jul. 2015. 